\title{
Experimental teaching reforms of optical fiber communication based on general education
}

L. Lan, S. Liu, J. Zhou, Z. Peng

L. Lan, S. Liu, J. H. Zhou, Z. M. Peng, "Experimental teaching reforms of optical fiber communication based on general education," Proc. SPIE 10452, 14th Conference on Education and Training in Optics and Photonics: ETOP 2017, 104524Y (16 August 2017); doi: 10.1117/12.2269486

SDIE Event: 14th Conference on Education and Training in Optics and Photonics, ETOP 2017, 2017, Hangzhou, China 


\title{
Experimental Teaching Reforms of Optical Fiber Communication Based on General Education
}

\author{
Lan L. ${ }^{1,2}$, Liu S. ${ }^{1,2}$, Zhou J. H. ${ }^{1,2}$, Peng Z. M. ${ }^{1,2}$ \\ (1. School of Optoelectronic Information, University of Electronic Science and Technology of China, \\ chengdu 610054, China; 2. Notional Virtual Simulation Experimental Teaching Center for \\ Optoelectronic Information Technology, University of Electronic Science and Technology of \\ China, chengdu 610054, China)
}

\begin{abstract}
It's necessary that higher education experimental teaching reforms on the basis of general education. This paper put forward the experimental teaching reform mode of optical fiber communication in the context of general education. With some reform measures such as improving the experimental content, enriching the experimental style, modifying the experimental teaching method, and adjusting the evaluation method of experimental teaching, the concept of general education is put throughout the experimental teaching of optical fiber communication. In this way, it facilitates the development of students and improvement of experimental teaching quality.
\end{abstract}

Key words: General education; experimental teaching; optical fiber communication; teaching reform

\section{CONNOTATION OF GENERAL EDUCATION}

The general education has a long history, which is originated in ancient Greece liberal education. It aims to cultivate all-round-developed persons who has the virtue and is suitable for free citizens of modern society. Before the 19th century, it generally referred to the floorboard of the primary and secondary school education. In 1892, the American College of Byrd Bowdoin College professor Packard A.S. first introduced the concept of general education to the university education. Since then, the general education concept spreads out. The American association of colleges and universities think general education can provide the multidisciplinary broad field of vision, offer foundation to improve the cognitive ability and the citizen accomplishment, and be required for all undergraduate students to learn ${ }^{[1]}$.

General education is a kind of education idea. And its core is education how to behave as a human ${ }^{[2]}$. At present, due to different national conditions and cultural background, the focus of education is different. But no matter China and foreign countries, the emphasis is general education, that is, through the knowledge integration of humanities, social and natural sciences to broaden the horizons. In the way of teaching, the general education advocates the question curriculum, the discussion curriculum, requiring student to train the thought, think independently with the value judgment and learn the research-based study. In the teaching method, the general education needs to respect the student's personality development, pay attention to the heuristic teaching and train the students to master the different subjects ${ }^{[3]}$.

14th Conference on Education and Training in Optics and Photonics: ETOP 2017, edited by Xu Liu,

Xi-Cheng Zhang, Proc. of SPIE Vol. 10452, 104524Y · ( 2017 ICO, IEEE, OSA, SPIE

CCC code: $0277-786 X / 17 / \$ 18 \cdot$ doi: $10.1117 / 12.2269486$ 
In the past, the general education and professional education is believed to be contradictory. First of all, the aim of general education is to cultivate the all-round development of people. And the goal of professional education is to train the skills to make people become experts. In addition, general education and professional education are contradictory in many aspects, such as the needs of the times and social requirements, personal learning ability, teaching content and educational philosophy. In fact, general education and professional education can be integrated ${ }^{[4]}$. The essence of general education is the education of all-round development, rather than a special form of education. We cannot think that only through the humanities education and the "second class" can we improve the students' humanistic quality and comprehensive quality. General education is embodied in the teaching practice of various subjects. It is a natural choice to promote the all-round development of people through the comprehensive integration of general education and professional education. The conflict between general education and professional education for a long time has caused serious consequences. The result of neglect of general education is that professional education has faced greater challenges and crisis of survival. Only the interaction between them can achieve a win-win situation.

In a word, strengthening general education has become one of the important measures in the development and reform of higher education. The combination of general education and professional education is not a simple addition and subtraction, but a comprehensive integration. On the basis of the integration of the two, it is necessary to make a further adjustment to the current general education, such as the form of implementation, curriculum content, curriculum components, so as to make it more reasonable.

\section{GENERAL EDUCATION IDEA INTO EXPERIMENTAL TEACHING}

Comprehensive science education requires not only teaching knowledge and technology, but also training scientific methods and thinking, and cultivating scientific spirit and moral character. This is just the most important task of general education. And the experimental teaching in colleges and universities is the important section to implement comprehensive science education and cultivate students' innovative consciousness and ability ${ }^{[5]}$. The experimental teaching is to make students feel and understand the emergence and development process of knowledge, learn and master the basic research methods of engineering technology, measurement methods and the necessary advanced equipment and various disciplines, cultivate students' scientific spirit, creative thinking habits and the ability of analyzing and solving problems ${ }^{[6]}$. So the goal of experimental teaching is the same to the general education idea, which is to attach great importance to the cultivation of the coordinated development of human beings and the ability to basic education, to cultivate the talents with a wide range of knowledge and strong adaptability, to guide the students to study the internal rules, grasp factual knowledge, explore and discover the principle of knowledge, and be able to creatively use knowledge. Therefore, it is of great significance and urgency to integrate the general education idea into the reform of experimental teaching in Higher Education.

General education is a multidimensional concept. Firstly, it is a kind of educational idea, which is accessible to everyone, moreover a philosophy for a university. Secondly, it means education contents to achieve the goals of general education purposes. Thirdly, it refers to an education model reflecting the education ideology. The educational idea, content and mode affect each other ${ }^{[5]}$. Generally speaking, the concept of general education emphasizes the comprehensive development of the individual, the people oriented. For the experiment teaching, this concept of general education is needed to instruct the deep reform of the teaching content and mode design from the height of guiding ideology。

The idea of the reform of the advanced experimental teaching is to explore the innovation of teaching idea, training mode 
and management mechanism. There are many modes for the reform of experimental teaching, such as putting "harmonious development and wide knowledge" into the teaching program, providing "heuristic teaching and research-based learning" into professional experimental skill training for students, setting idea of extensive learning and multi-potency into experimental learning, improving the quality of teachers and promoting the construction of cultural environment ${ }^{[3,5]}$. Among them, the strengthening of heuristic teaching and research-based learning is the key to general education in experimental teaching. The heuristic teaching and research-based learning is to inspire students to treat the learning object as the research object, research the internal rules of knowledge, accept and grasp factual knowledge, explore and discover the principle of knowledge, and be able to creatively use the knowledge . Therefore, we should reform the experimental teaching content and teaching methods according to the cultivation of students' experimental ability.

\section{EXPERIMENTAL TEACHING REFORMS OF OPTICAL FIBER COMMUNICATION}

In modern society, with the rapid development of optical fiber communication technology and related information industry, under the guidance of scientific research and talent demand, the importance of optical fiber communication experimental teaching is becoming more and more obvious. Optical fiber communication experiment is a professional course facing the major of optical information science and engineering. Through this experiment course, students can grasp the basic theory of optical fiber communication, and understand the theory knowledge of fiber structure and link characteristics, fiber optical devices and optical fiber communication system. Meanwhile, the course teaching can stimulate the students' interest in learning, exercise the ability of their independent thinking and innovation, and enable students to have a strong professional experiment ability and certain system design ability and engineering practice ability $^{[7,8]}$.

With the update and development of optical fiber communication technology, the progress of teaching methods and equipment, as well as the problems found in the process of experiment teaching, the optical fiber communication experimental teaching also needs to reform ${ }^{[9,10]}$. For a long time, in many colleges and universities, the content of the experimental teaching is old. And the teaching mode and method is monotonous. It greatly limits the effective cultivation of students' critical thinking. And it is difficult to stimulate their interest and passion in the study of the problem. Then their ability to acquire, organize and apply information and create new information is poor. Therefore, it is necessary to promote the reform of the experiment teaching within general education idea. Teaching reform measures include the following aspects.

\subsection{Improving the experimental content}

In the concept of general education, focus on foundation and wide range is needed, which is also the requirement of experimental teaching content. At the beginning of the experiment course of optical fiber communication, only two experiments were carried out, such as optical fiber cutting and welding experiment and optical fiber attenuation coefficient measurement. It cannot cover the key content of optical fiber communication technology. After that, the test of optical passive devices, the measurement of digital optical fiber communication system and the experiment of wavelength division multiplexing technology are gradually added. Through the improvement, the content of the current experimental course has covered the important knowledge points of the optical fiber communication technology. We 
have set up a series of experimental projects from fiber to optical fiber communication system, including the measurement of optical fiber characteristics, the performance test of optical fiber communication devices, the test of digital optical fiber communication system and the experiment on new technology of optical fiber communication. The optical fiber characteristics required to be measured includes the geometrical and transmission loss characteristics. The transmission loss of optical fiber is tested by using the method of insertion and optical time domain reflection. The performance test of the optical fiber communication device includes the test of the light source and the passive component. Optical passive devices include several common passive devices, such as optical coupler, optical isolator, optical attenuator and optical circulator. The experiment on new technology of optical fiber communication is based on the two most important technologies, optical wavelength division multiplexing and optical amplification. Through the improvement of the teaching content, the students complete the progressive learning from the basic components of the optical fiber communication system to the device and finally to the system. It forms a more systematic and complete knowledge system, which helps students consolidate and strengthen the study of optical fiber communication technology.

\subsection{Enriching the experimental style}

In the past, the experimental teaching method is usually the verification, that is, given the existing results, students only need to verify some theorems and conclusions through the established operation. This single verification experiment will ignore the principle, strategy, development and creative quality of teaching [11]. The content of the course is lack of stimulation and challenge to the development of students' intelligence. So we should enrich the experiment style. Under the background of general education, heuristic teaching and research-based learning also need to change from demonstrative and confirmatory experiments to research and comprehensive experiments. In the experiment teaching of optical fiber communication, there are three kinds of experimental types added, such as comprehensiveness, design and innovation. The comprehensive experiment is that the experiment involves a number of related knowledge points, such as the measurement of the optical fiber characteristics and the test of the characteristics of optical active devices. The design experiment refers that the students design the experiment scheme and realized the experiment with the designed target, content and conditions . The experiment of optical passive device and the optical fiber communication system are this type of experiments. In the innovative experiment, the experiment content and equipment are completely open to students. Students can complete the whole process of experimental design, raw material preparation, experimental data collection and result verification. It is beneficial for comprehensive training of students' experimental skills and improvement the ability to analyze and solve problems. The experiment of erbium-doped fiber amplifier is this type of experiment. Students can design the structure of amplifier to realize the function. And the characteristics of the amplifier can also be tested. On this basis, students can even design and implement the erbium-doped fiber laser with various structures.

\subsection{Modifying the experimental teaching method}

Teachers should not only be the propagator of knowledge, but also the builder, leader and illuminator of a learning process. The heuristic teaching and research-based learning mode in general education can also be applied to the improvement of optical fiber communication experiment teaching methods.

On the one hand, teachers give the guidance and Inspiration of pre class preparation. To provide students with two documents, one is the experimental textbook, and the other is the experimental teaching arrangements. The students can 
preview the corresponding experimental teaching knowledge according to the teaching process. Teachers do not make uniform requirements of the preparation method, but ask the students to write the preview report and ask questions.

On the other hand, teachers should guide students and interact with them in the experimental teaching. Teachers should not be busy with demonstrations and lectures, but inspire students to think and question. Through interactive teaching, students become the subject in teaching. Teachers should respect students' ideas, encourage students to analyze and solve problems from multiple perspectives so as to truly understand and expand knowledge through research learning. At the same time, the cooperative experiment is promoted by grouping experiment. Students not only communicate with teachers, but also interact with students.

\subsection{Adjusting the evaluation method of experimental teaching.}

Based on the single training evaluation, students with innovative ideas is less and less. It is difficult to cultivate students into generalists. Therefore, the experimental evaluation system of optical fiber communication is adjusted to multi stage evaluation. The results of the experiment include three stages, namely, the experiment preview, the experimental operation and the experimental results. Their proportion is $10 \%, 30 \%$ and $60 \%$.

\section{CONCLUSION}

Experimental teaching is an important part of higher education. The level of experimental teaching directly affects the level of teaching and scientific research in Colleges and universities. The concept of general education provides a new perspective and method for the reform of experimental teaching in Colleges and universities, which provides a new thought to embody the spirit of education based on the harmonious development of students. The experimental teaching of optical fiber communication in the concept of general education is not only to impart knowledge and technology, but also to train students' scientific methods and thinking and cultivate students' scientific spirit and moral character. It is very necessary and important to mobilize the initiative of students, cultivate students' innovative spirit and learning ability, and guide students to develop in an all-round way.

\section{REFERENCES}

[1] Levine A., Handbook on undergraduate curriculum, Jossey-Bass Publishers, San Francisco, 697(1987).

[2] Pang H. S., "The three phases of general education: ideology, content and mode", Fudan Education Forum, 5(1), 24-29(2007).

[3] Ma X. C., "Experimental teaching reform mode on the basis of general education idea", Research and Exploration in Laboratory, 28(12), 119-121(2009).

[4] Zhu J. L., "The conflict and integration of general education and professional education in Universities", Higher Education Research in China, 6, 17-19(2002).

[5] Gao X., "Strengthening General Education in experimental teaching", Chinese University Teaching, 11, 84-86(2012).

[6] Wang M. X., "Laboratory teaching -a necessary condition for the training of innovate students", Laboratory Research and Exploration, 8(21), 25-28(2002).

[7] Liu Q., "Research on the teaching of optical fiber communication", Teaching Research, 31(3), 240-242(2008). 
[8] Zhang S. E., Li Y. Q., Yang Z. W., "Discussion on construction of experiment of excellent course-fiber communication principle", Experimental Technology and Management, 27(5), 165-166(2010).

[9] Long Q. Y., Zuo J. L., "Experimental teaching reform of optic fiber communication based on engineering with a big E", Research and Exploration in Laboratory, 31(8), 342-345(2012).

[10] Cao X., Li X. Y., "Discussion and optimization of experimental teaching for optical fiber communication", Experiment Science and Technology, 11(1), 97-99(2013).

[11] Lan L., Zhou J. H., Qiu Q., Wu Y. M., “Experimental teaching reforms of optical fiber communication”, Research and Exploration in Laboratory, 33(7), 437-438 (2014). 